\title{
Religiosidad Indígena y Conflicto en Guatemala
}

\author{
Juan Luis Ramírez Torres \\ Centro de Investigación y Estudios Avanzados en Salud \\ Pública, UAEM
}

\section{Introducción}

Las décadas recientes en Centroamérica se han caracterizado por movimientos sociales que han optado por la vía armada, Nicaragua, El Salvador y Guatemala, principalmente, tejen su historia inmediata bajo la fuerte influencia de las organizaciones sandinista, farabundista y de la Unidad Revolucionaria Nacional Guatemalteca, todas agrupaciones políticas armadas. Las consecuencias de esta situación aún no terminan, por lo pronto, la dictadura somocista ha concluido; entre los salvadoreños la situación quedó sin vencedores ni vencidos después de alcanzarse el término de las hostilidades; en Guatemala la insurgencia todavía continúa, sin que las negociaciones que se llevan a cabo desde hace varios años lleguen a un feliz término.

En este último país, la dinámica de guerra ha estado caracterizada por el profundo sentido indígena de sus habitantes dada la herencia cultural maya, la permanencia de regiones polarizadas desde el periodo colonial entre indios y ladinos (no-indígenas), en una palabra, el carácter étnico de esta nación hace de su experiencia política contemporánea, un referente ilustrativo sobre los comportamientos bélicos en el contexto latinoamericano: con un pasado precolombino, un periodo de sojuzgamiento colonial y un relación político económica con los Estados Unidos de Norteamérica que la han marcado durante el siglo que ya termina.

De esta manera, la diversidad pluriétnica heredada de sus antecedentes prehispánicos, el sincretismo religioso gestado durante la Colonia y las actuales influencias derivadas de la globalización actual dan por resultado que las regiones latinoamericanas elaboren experiencias "heterogéneas" ante los ojos que, desde una ortodoxia caduca, se confunden frente a acontecimientos sociales que combinan trozos de acervos culturales distintos para construir nuevos sistemas que los tiempos que corren exigen. La historia de Guatemala guarda enseñanzas, el recorrido por ella que ahora se presenta, intenta ofrecer un referente de cómo en contextos sociales dramáticos, con fuentes ideológicas y políticas diversas, se pueden construir nuevos sistemas de acción social. 
Convergencia Revista de Ciencias Sociales, núm. 12/13, 1996, Universidad Autónoma del Estado de México

\section{Historia reciente de Guatemala}

La historia inmediata guatemalteca puede ser entendida en tres etapas: 1) la revolucionaria, comprendida de 1871 a 1944; 2) la revolucionaria, de 1944 a 1954; y 3) la contrarrevolucionaria, de 1954 hasta nuestros días (Vargas, 1984). Esta división, si bien corresponde a puntos de cambio político calificados a partir de una posición igualmente política, coincide con otros puntos de modificaciones económicas. Este criterio guía la exposición.

Guatemala Independiente. Hacia finales del siglo XVIII, lo que hoy es Guatemala, era parte del llamado reino de Guatemala, y que además era integrado por las provincias de Costa Rica, San Salvador, Camayagua -en el actual Honduras- y León -en Nicaragua-; el actual estado mexicano de Chiapas quedaba comprendido en dicho reino y bajo el gobierno de la provincia de Guatemala. El territorio guatemalteco declara su independencia en el mes de septiembre del año de 1821; en 1822, sumado a Centroamérica, se anexa al llamado Imperio de México encabezado por Agustín de Iturbide, episodio de corta vida, ya que en 1823, se forma el primer gobierno centroamericano, el cual se declara independiente tanto del de España como de México. Sin embargo, para 1824 Chiapas se integra a México, por lo que su territorio deja de pertenecer a la naciente república identificada con el nombre de Provincias Unidas de Centroamérica y cuya capital se instalaba en Guatemala. Esta forma republicana de América Central se rompe en 1838, por lo que Guatemala, al igual que las otras provincias, pasa a constituir gobiernos independientes, perfilándose así las actuales naciones que conforman a dicha región del continente.

Las numerosas poblaciones indígenas y antiguas habitantes, no participaron ampliamente del movimiento independentista, así lo muestran hechos como el rechazo mostrado por parte de los criollos insurrecto s para con la ayuda ofrecida por Manuel Tot, el cual ponía a disposición de la causa antiibérica a 60000 indígenas kekchíes, o el haber dejado sin apoyo a la revuelta de Atanasio Tzul en Totonicapán (Arias, 1984: 149). A mediados de ese mismo siglo pasaban del $70 \%$ las tierras tituladas en propiedad y pertenecientes a las comunidades campesinas, de las que una buena parte eran pueblos indígenas. Instaurados los gobiernos independientes, se realizan cambios en lo económico; en algunos momentos de la Colonia se observó el cultivo del cacao, pero no tuvo posibilidades de mantenerse; por el contrario, ya desde el siglo XVIII, se exporta a los mercados europeos la tinta de añil, destinada a la industria textil; posteriormente su lugar es tomado en el siglo XIX, por la grana, sin embargo, la aparición de tintes procesados por la industria química hace que decaiga esta actividad. 
Un nuevo producto de exportación se presenta: el café. Ligados a estos cultivos, siempre estuvo la fuerza de trabajo campesina, indígena en proporción relevante. Desde principios del mismo siglo XIX venía practicándose su cultivo, antecedente que permitió, después de la caída de la grana, que comenzara a ocupar cada vez mayores superficies agrícolas; pero se encontraba las fronteras territoriales de numerosas comunidades campesinas, motivo por el cual se veía frenada su expansión. Dominaban los gobiernos conservadores, iniciados por el General Rafael Carrera en 1839 y que se prolongan hasta 1871, momento en que toman el mando los liberales, con Justo Rufino Barrios a la cabeza e iniciándose la Reforma Liberal. Esto corría paralelo al cambio en los cultivos de exportación, por lo que ejercen una especial influencia las reformas promovidas por los nuevos gobernantes. Mientras que en los gobiernos conservadores la grana permitía la reproducción del esquema doméstico económico -correspondiente a las familias campesinas-, que a su vez, induce a pensar que reforzaba las microestructuras sociales de las comunidades indígenas, el café, por el contrario, exige amplias superficies agrícolas y numerosa fuerza de trabajo por estaciones. Ante estos nuevos requerimientos, las características sobre la tenencia de la tierra resultaban poco favorables, ya que entre 1866 y 1870 ésta se encontraba en las siguientes condiciones:

1. Tierras adquiridas con título legítimo.

2. Terrenos titulados ad corpus.

3. Terrenos poseídos por personas que carecían de títulos de propiedad.

4. Ejidos de municipalidades y tierras comunes de los pueblos de indios.

5. Tierras de propiedad de las comunidades religiosas.

6. Tierras de las cofradías religiosas indígenas.

7. Terrenos de las fundaciones de festividades religiosas. (Guerra, 1987: 124)

Con las reformas de Justo Rufino Barrios en esta materia, se afectaron las propiedades de las comunidades religiosas, las cofradías y las fundaciones de festividades religiosas. Si bien, a través de ellas se disminuyó el poder de la Iglesia Católica, es también cierto que las comunidades religiosa resultaron afectadas de tal suerte que las mencionadas exigencias de tierra y fuerza de trabajo empezaban a ser satisfechas. Así las cosas, formas de producción entendidas como características del capitalismo, penetraban en la vida, ahora nacional, de la economía guatemalteca. En los albores del siglo XIX se inicia la llegada de los capitales estadounidenses que abarcaban los ferrocarriles, los puertos y los medio de comunicación marítima. Por igual, se fomentan otros cultivos como los del banano, caña de azúcar, tabaco y arroz 
Con todo, las disposiciones en materia agraria no repercutieron sobre las poblaciones indígenas como se podría suponer, este periodo "tuvo muy poco impacto político en el Altiplano indígena" (Manz, 1986: 20); tales afirmaciones encuentran sustento en las cifras arrojadas por el número de fincas afectadas por el Decreto 900, entre enero de 1953 y junio de 1954, en donde, para los departamentos de sobre- saliente población indígena, como son los casos de Huehuetenango y El Quiché, del total de fincas implicadas (1'091,073 has.), únicamente correspondieron a dichos departamentos un 4.6 y un 5.9 $\%$, respectivamente, frente a u $27.2 \%$ alcanzado en el departamento, poco indígena, d Escuintla (EFCCEO-CIDA, 1971: 98).

Lo anterior no quita el hecho de que gracias a la reforma agraria impulsada durante esa etapa, de un $31 \%$ a un $40 \%$ d los campesinos sin tierra la adquirieran. Tampoco niega que finalmente, los sectores poderosos ubicados en la economía agraria del país se vieran afectados: Jacobo Arbenz es derrocado por medio de una rebelión armada que dirige el coronel Castillo Armas. Termina violentamente un periodo calificado ya de democrático, ya de revolucionario, pero en donde resultaron beneficiados estratos campesinos y se actuó desde un espíritu nacionalista.

Los años posteriores a 1954. Se llega a considerar el periodo 1944-1954 como una "revolución democrático-burguesa anti-imperialista [...] se instaura definitivamente el capitalismo como modo de producción dominante en Guatemala, lo que permitió un reacomodo y definición del desarrollo sociopolítico y económico del país" (Vargas 1984: 14-5). El sentido "democrático-burgués" y "capitalista" no quitó la carga nacionalista y antiimperialista, dirigid hacia los Estados Unidos particularmente y concretada e empresas como la United Fruit Company. De tal manera es que, caído Arbenz, el nuevo gobierno emite el Decreto 31 que prácticamente anula a su antecesor, el Decreto 900. Se estima entonces que “... el movimiento armado de Castillo Armas era parcialmente producto de la reacción de la clase terrateniente contra el Decreto 900..." (EFCCEO-CID, 1971: 108).

Durante estos años el clero católico se mostró identifica do con los terratenientes (Guerra-Borges, 1987: 143), que dando lejanos aquellos tiempos de conflicto Estado-Iglesié: posterior a 1954 llegan a Guatemala sacerdotes extranjero "imbuidos de una fuerte ideología anticomunista" (Maro 1986: 27) derivada de su condición de españoles asociado con el franquismo dominante en su nación de origen. Para este momento, en Guatemala, existe el organismo eclesiástico Acción Católica, cuyos orígenes más primitivos se remontan a 1934, ubicados en Totonicapán, sitio en que se forma la Sociedad de Propagación de la Fe; en 1945, se constituye a nivel diocesano dando 
De la Colonia a estos años, las poblaciones indígenas venían dando muestras de reacción social frente a los acontecimientos económicos y políticos que influían negativa mente sobre sus economías tradicionales. Como muestra de tales reacciones se pueden citar varias insurrecciones ocurridas entre estas etapas de vida colonial e independiente: mames de Ixtahuacán, en 1743; de Santa Lucía Utatlán, en 1760; kakchiqueles de Técpan, en 1764; kekchíes de Cobán en 1770; mames de San Martín Cuchumatanes, Santiago Momostenango en Ixtahuacán, en 1813; quichés de Totonicapán, en 1820; Canjobales de San Juan Ixcoy, en 1898; y, nuevamente los quichés de Totonicapán, en 190 (Arias, 1984: 152).

El periodo 1944-1954. A las reformas impulsadas por Rufino Barrios sigue un largo periodo gubernamental presidido por Manuel Estrada Cabrera, cuya duración fue de 189 a 1920. Durante esta etapa se experimenta una disminución en el crecimiento económico. Estas dos décadas concluye cuando el terrateniente azucarero, Carlos Herrera, liderea un movimiento que derroca a Cabrera. Se suceden entonces un serie de gobiernos que no logran una regularidad constitucional hasta que toma el gobierno el general Jorge Ubico Castañeda, pero cuyo carácter es considerado por alguno autores como "el último de corte típicamente oligárquico (Guerra-Borges. 1987: 138). Se inicia el periodo 1944-1954 considerado como un momento clave en la historia Contemporánea guatemalteca; las razones de ello se basan en las acciones gubernamentales que tendieron a ofrecer una serie de beneficios sociales y que afectaron intereses de terratenientes y empresas transnacionales.

Habiendo dejado el poder Ubico, toma el mando de la Nación Juan José Arévalo Bermejo, a quien seguiría, en 1954, Jacobo Arbenz. Sin bien este último actuaría más decididamente, ambos periodos son comprendidos como partes de una misma etapa. De entre las diversas disposiciones tomadas, se puede considerar que las relativas en materia agraria fueron las de una especial repercusión, tal vez, más política que económica. Es así que, durante dichos gobiernos se emitieron decretos (Decreto 712 y Decreto 900, para cada gobierno respectivamente), los cuales perseguían generar una mayor producción agrícola destinada al mercado de la que participaran las capas campesinas, de tal suerte que se impulsó una reforma agraria que contemplaba mejora- miento técnico, créditos y reparto de tierras. Estas acciones no fueron del agrado de terratenientes ni capitales extranjeros- de los que participaban compañías estadounidenses como la United Fruit Company-, a pesar de que el mismo Jacobo Arbenz, en su calidad de Presidente de la República declaraba su intención de "convertir a Guatemala, de país atrasado y de economía predominantemente feudal en un país moderno y capitalista”. 
pie a la Acción Católica Nacional, la que participa en contra del comunismo. Derrocado Jacobo Arbenz y nutrida Acción Católica por los sacerdotes españoles, se relaciona con la Democracia Cristiana Guatemalteca, a la vez que realiza un trabajo que incluye construcción de escuelas, castellanización, lucha contra el alcoholismo, enseñanza de nuevas técnicas agrícolas, adoctrinamiento católico y formación de cooperativas; en estas tareas participaron tanto misioneros, como catequistas y delegados de la palabra. Cabe señalar que dichas acciones resultaron opuestas a las formas tradicionales mantenidas por las comunidades indígenas (Arias, 1984).

Se suceden los gobiernos del ya mencionado Castillo Armas, quien es asesinado en 1957; le siguen, en 1958, Miguel Ydígoras Fuentes; en 1963, el coronel Enrique Paralta Azurdia; 1966, Julio Cesar Méndez Montenegro; 1970, coronel Carlos Arana Osorio; 1974, general Eugenio Kjell Laugenrud. En 1978, se rompe la dinámica de presidentes nombrados en elecciones -a excepción de Peralta Azurdia que toma el poder a través de un golpe de estado-, ya que el nuevo presidente, general Romeo Lucas García, es designado por la Asamblea Legislativa, a partir de ese año, los acontecimientos, ya de por sí graves, se agudizan.

Detenidas las medidas agrarias impulsadas entre 1944 y 1954, ya en la década de los sesenta, el capital monopólico internacional concentra su inversión en la explotación de recursos naturales no-renovables, particularmente el níquel y petróleo, explotación que se realiza en la región que abarca el norte de los departamentos de Izabal, Alta Verapaz, El Quiché y Huehuetenango (Aguilera, 1981: 13). A su vez, los oficiales del ejército participan en calidad de coinversionistas de los capitales estadounidenses. Para 1962 se emite una Ley de Reforma Agraria, pero cuyos resultados no son significativos.

Por su parte, las comunidades indígenas implementan estrategias que les permite responder a la insuficiencia de tierra originada por el avance del minifundismo, para lo cual echaron mano de opciones como la de reestructurar el uso de la tierra en forma de cooperativas -ocurrido en el nordeste de Huehuetenango, norte de El Quiché y occidente del Petén, al final de los sesenta y en la década de los setenta-; o bien, emigrar en busca mejores opciones económicas (Manz, 1986: 22).

Mientras los gobiernos se suceden, en el seno mismo del ejército se gestan embriones de organizaciones armadas opuestas a los regímenes. De acuerdo a la información proporcionada por el artículo La violencia en Guatemala, de Gabriel Aguilera Peralta (1981), una primera manifestación de ello ocurre el13 de noviembre de 1960 cuando oficiales subalternos se alzan en armas; de este acontecimiento se deriva la organización Movimiento Rebelde 13 de 
Noviembre (MR -13 N) aparecida en 1961. La reacción armada de estos oficiales, responde a la .corrupción observada tanto en la administración del General Ydígoras como en el mismo ejército, además de mostrarse inconformes por la presencia en territorio nacional de brigadas de cubanos anticastristas, lo cual resultaba contrario a sus convicciones nacionalistas. El Partido Guatemalteco del Trabajo, al realizar su tercer congreso en 1960, determina incluir entre sus formas de lucha la vía armada, por lo cual, en 1962, abre un frente guerrillero bajo el nombre 20 de Octubre. Posteriormente nacen las Fuerzas Armadas Rebeldes (F AR), conformado por el Movimiento Rebelde 13 de Noviembre, el Movimiento 12 de Abril, nutrido éste por estudiantes, y el Movimiento 20 de Octubre. Entre 1963 y 1966, el movimiento armado logra un periodo de auge a pesar de que en 1964 sufre escisiones. Sin embargo, de 1966 a 1968 la guerrilla entra en una fase de derrotas militares las que coinciden con la participación de asesores militares estadounidenses pertenecientes al grupo denominado boinas verdes, quienes aplican técnicas y tácticas contrainsurgentes por ellos utilizadas con anterioridad en Vietnam (Arias, 1984). A pesar de que el movimiento armado intenta reorganizarse entre 1968 y 1973 no logra reponerse de las derrotas sufridas.

La participación popular en la guerrilla no fue un rasgo presente en ella, nutriéndose principalmente de estratos me- dios de la sociedad (Aguilera, 1981); tal vez la excepción fue materializada por Emilio Ramón, líder cakchiquel que se incorpora junto con otros indígenas a la agrupación Frente Guerrillero Edgar Ibarra (Arias, 1984: 156). Posiblemente, al observar esta ausencia es que, a principios de los setenta, tanto las FAR como el PGT, tienden a fortalecer su relación con los sectores populares.

La década de los 70 vive un giro en los movimientos sociales, ya que aparecen organizaciones populares que aglutinan amplios conjuntos de personas. En este proceso participa la ya antes mencionada, Acción Católica; en 1961 la Democracia Cristiana Guatemalteca, con la que mantenía nexos, es declarada ilegal; en 1965 se constituye la Federación Guatemalteca de Campesinos, entidad cuyos dirigentes formaban parte de la Democracia Cristiana, las respuestas que reciben son acusaciones de ser comunistas, la que se hace extensiva a los sacerdotes de Acción Católica (Arias, 1984: 157). Paradójicamente, este organismo religioso pasa así de anticomunista a sospechoso de comunista.

Paralelo a este proceso de Acción Católica ocurre la formación de un organismo campesino de especial relevancia, este es el Comité de Unidad Campesina (CUC), fundado en 1978 pero con antecedentes que van a 1973, momento en que los futuros integrantes del CUC tenían pláticas de reflexión sobre La Biblia, cursos de alfabetización y mucha discusión relati- 
va a sus problemas principales, (Fernández, 1988: 5). Ya constituido como CUC el 24 de abril de 1978 difunde un comunicado en que expresa su voluntad de aglutinar a las organizaciones campesinas existentes e impulsar la lucha conjunta de obreros y campesinos; el 1o. de mayo de ese año, participa en una manifestación celebrada en la ciudad de Guatemala a propósito de la conmemoración de los Mártires de Chicago. El mismo Arturo Arias considera que "son estos hombres [los derivados de AC] los que realizan la necesidad de una organización no a nivel regional, sino nacional, y que fundan el Comité de Unidad Campesina” (Arias, 1984: 157).

En el contexto de una lucha política que va aglutinando masivamente a los sectores populares es que aparece un nuevo organismo: el Ejército Guerrillero de los Pobres en 1975. Esta agrupación, coincide geográficamente con el CUC en la región conocida como Ixil, sitio en donde se ubica población indígena (Fernández, 1988: 11). Por igual hacen acto de presencia dos guerrillas más, Organización del Pueblo en Armas (ORP A) y las Fuerzas Armadas Rebeldes (FAR), grupo que resulta ser el más cercano a los nexos con la guerrilla de los sesenta (Manz, 1986: 28).

Las movilizaciones políticas adquieren un carácter masivo, hecho que se patentiza en casos conocidos como las Jornadas de Agosto, en 1977, y las Jornadas de Octubre, en 1978. La nueva efervescencia permite que el movimiento guerrillero cobre auge "en tomo a 1978, momento de gran desarrollo del movimiento popular..." (Fernández, 1988: 13). Pero el gobierno guatemalteco no dejaba correr libre- mente los acontecimientos, en mayo de ese mismo año, se ejecuta la masacre sucedida en el municipio de Panzós, departamento de Alta Verapaz teniendo por resultado 100 víctimas; a finales del mismo 1978, cerca de 50 mujeres exigen la aparición de sus esposos, entre los que, por cierto, se cuentan dirigentes de AC y cooperativistas. Para 1979 se estima que entre 100 y 200 personas son asesinadas mensualmente entre opositores al gobierno (Manz, 1986: 28). Ocurren otras masacres en Chajul, Nebaj, Uspatán, todos ellos municipios de El Quiché. Estos acontecimientos propician que en 1980 se tome la Embajada de España en Guatemala, ante lo cual la respuesta oficial es su evacuación por fuerzas del ejército el 31 de enero de ese año, teniendo por saldo 39 víctimas.

Surge una espiral de violencia, a la represión oficial se le responde incrementando la influencia guerrillera, en 1981 los grupos armados mantienen presencia militar en 9 de los 22 departamentos que componen a la nación guatemalteca (Manz, 1986: 29). Ahora la represión no se ejerce exclusivamente sobre individuos sino que se cambia, como los movimientos populares, a una represión masiva. Este proceso es observable en lo que Aguilera Peralta deno- 
mina las cuatro olas de terror, entendidas "cuando la violencia afecta más directamente a los cuadros dirigentes nacionales de las organizaciones populares y a la intelectualidad progresista así como a sectores más amplios de las capas medias, tendiendo a configurar un sistema de terror" (Aguilera, 1981: 16). Estas olas las ubica el autor de la manera siguiente:

$1^{\text {a }}$. Noviembre de 1966 a marzo de 1968 . Ataque de grupos paramilitares a personas;

$2^{\text {a }}$. Efectuada por el grupo paramilitar Ojo por Ojo;

3a. Periodo de Arana Osorio, de carácter más selectivo; y,

4a. Periodo de Kjell Laungerud García.

El generar terror entre los opositores ya se usaba desde la llegada de asesores estadounidenses que aplicaron tácticas probadas en Vietnam, pero ahora el terror se extendía sobre la masa.

\section{Comunidad indígena, Iglesia y guerrilla}

Permanencia y vigencia de la comunidad indigena hoy. Para los momentos en que ocurren los sucesos mencionados, las comunidades indígenas observan una permanencia orgánica cuyos antecedentes se remontan a la Colonia. Continua la comunidad cohesionada, en donde la posesión de una extensión territorial-destinada fundamentalmente a la agricultura, pero en la que por igual, se asientan las viviendas, se crían los animales, se crean y recrean las culturas correspondientes a cada comunidad- hace un cuerpo social al que se pertenece por haber nacido en ese sitio, y por haber sido procreado por miembros de esa misma comunidad. Estas poblaciones, ahora afectadas por el minifundismo, abriéndose a la emigración para lograr ingresos monetarios vía trabajo asalariado y comercio, con la presencia de cooperativas, implican cambios en sus formas culturales, modificaciones que pueden ser entendidas como síntomas de desintegración cultural y comunitaria, que al ser experimentada por conjuntos étnicos, llevaría a su desaparición como indígenas.

Sin embargo, pereciera ser que los cambios culturales y económicos ocurridos no son factores determinantes para desmembrar las comunidades étnicas guatemaltecas, existe un sistema de organización que resulta más integrado en comparación con las formas innovadoras. Este sistema consiste en dos partes, una la organización municipal, y la otra, la organización religiosa estructurada en el sistema de cargos.

El sistema municipal heredado de la Colonia permanece hasta nuestros días, y es este sistema el que se constituye en receptáculo de los pueblos indígenas cuyos antecedentes van más allá de la Colonia, ambos-municipio e 
indígenas- se fusionan generando espacios étnicos. La cantidad de estos espacios no equivale al número de lenguas indígenas habla- das -poco más de veinte-, el asunto es mucho más complejo. Es así que Sol Tax -investigador especialista de la situación étnica guatemalteca-, cuestiona la asociación simple entre lengua y grupo étnico, él nos dice: "Los indígenas de hoy que hablan dialectos de una lengua (como quiché y cakchiquel) no están en sentido alguno organizados como un grupo social [...] Los términos lingüísticos no pueden ser usados incontrovertiblemente, por tanto, para designar grupos étnicos", es sobre lo anterior que avanza sobre una perspectiva alternativa: "La gente en Guatemala vive en municipios que son divisiones territoriales administrativas, generalmente reconocidas en todos los asuntos gubernamentales, pero que también son -como ocurre en efecto- las divisiones étnicas básicas y los grupos culturales en los que está dividido el país". Por tal motivo es que considera a los municipios como entidades individuales (Tax, 1965: 11).

Ahora bien, estas entidades individuales vistas por Sol Tax, no son producto únicamente de una división municipal formal, su permanencia factual radica en la reproducción social ejercida por los mismos integrantes de esas entidades. Esta reproducción social se efectúa de manera especial por medio del sistema de cargos, es decir, por medio de una instancia igualmente heredada de la Colonia pero bajo una forma religiosa, que no civil, como la primera. El sistema de cargos o cofradía, sin embargo, posee una mayor autonomía que la instancia municipal, respecto a los poderes dominantes.

Hay que recordar que los municipios, además de contar con un ayuntamiento, han mantenido un templo católico en el cual se ofrece culto a un santo en particular y que es considerado como su santo patrono, éste junto con otros santos pertenecientes a unidades integradas al municipio -aldeas, cantones-, reciben culto por medio precisamente de las cofradías, quienes se encargan de organizar las ceremonias correspondientes a cada imagen. De tal forma, municipio y sistema de cargos se entrelazan a la vez que como sistema de gobierno, en calidad de factor de cohesión y reproducción social de cada entidad municipal con particularidades culturales étnicas.

Comunidad indigena e Iglesia Católica. Es de comprenderse que la religiosidad practicada en estas comunidades indígenas se inscribe en la religiosidad popular, la cual, a su vez, se relaciona con la religiosidad oficial, en este caso, la institución eclesial católica. Dicha relación, no ha sido siempre ni de mero adoctrinamiento, ni de contradicción entre un supuesto paganismo opuesto al catolicismo oficial; ya al reseñar el desarrollo de Acción Católica se ha podido ver el cambio de un sacerdocio anticomunista a un sacerdocio identificado con luchas populares asociadas a ideologías cercanas al pensa- 
miento marxista. Para comprender este tránsito, es necesario retomar los acontecimientos en la Iglesia Católica ocurridos a partir del Concilio Vaticano II y las conferencias efectuadas para Latinoamérica en Medellín y Puebla. Ahí se confrontan dos posiciones teológicas y políticas: una, representada por los llamados conservadores, y otra, por los progresistas. La segunda tendencia elabora una versión latinoamericana que ofrece una nueva concepción teológica, la cual se plantea una "opción preferencial por los pobres"; esta nueva corriente es conocida en lo subsiguiente como Teología de la Liberación. Sus primeras manifestaciones sistematizadas aparecen en una obra pionera a la vez que fundamental y de vigencia contemporánea, escrita por Gustavo Gutiérrez bajo el título precisamente de Teología de la liberación, en el año de 1971; en ella se plantea una teología liberadora de las condiciones particulares de injusticia habidas en América Latina (Gutiérrez, 1984: 9).

A este autor se suman posteriormente otros sacerdotes como Leonardo Boff, quien entiende a esta postura en los términos siguientes:

"Según el sentido que demos a 'liberación', sea como tema, sea como acción que libera la libertad cautiva (por eso, liberación), cambia profundamente la comprensión de la Institución romana. En este punto se diferencian las dos perspectivas, aquella centroeuropea y ésta típicamente tercermundista y latinoamericana." (Boff, 1987: 51).

En la misma línea Ion Sobrino apunta a propósito del pecado:

"En la teología moderna el análisis recae mayoritariamente en el análisis de la interpretación de una realidad como pecado, en la comparación de esa interpretación con el análisis bíblico de pecado, etc.; mientras que en la teología latinoamericana lo que interesa en directo es constatar que hay pecado y reflexionar sobre el modo de quitarlo. El interés teológico no consiste entonces formalmente en esclarecer lo más exactamente posible en qué consiste la esencia del pecado, cuál sea el significado de un mundo de pecado, cómo pueda tener sentido la existencia del hombre en este mundo, sino en transformar esa situación de pecado." (Sobrino; 1977: 153).

Resulta evidente con las citas anteriores, el interés por parte de esta concepción católica, por una acción social concreta sobre las condiciones existentes en Latinoamérica, que permitan transformar las "situaciones de pecado", el cual es entendido en los términos que se pasan a exponer:

"El pecado en tanto que ruptura con Dios es una realidad histórica, es quiebra de comunión de los hombres entre ellos, es repliegue del hombre sobre sí mismo. Repliegue que se manifiesta en una multifacética postura de ruptura con los demás. Y por que el pecado es una realidad intrahistórica -personal y social-, formando parte de la trama diaria de la vida humana, es también, y ante todo, una traba para que aquélla llegue a la plenitud que llamamos salvación." (Gutiérrez; 1984: 187-8). 
En consecuencia, ante una situación de pecado se presenta la necesidad de liberación, de salvación, pero ésta se realiza particularmente con una parte de la humanidad, de la sociedad latinoamericana: el pueblo, especialmente el pueblo pobre: "El 'pobre', hoy, es el oprimido, el marginado por la sociedad, el proletario que lucha por sus más elementales derechos, la clase social explotada y despojada, el país que combate por su liberación." (Gutiérrez, 1984: 371).

Es esto lo que hace la opción preferencial por el pueblo, lo que en el terreno político latinoamericano significa una alianza, en este caso, una alianza política entre sectores populares y porciones del sacerdocio católico. Las concepciones teológicas de Gustavo Gutiérrez plantean:

"Sin embargo, las estructuras actuales impiden la participación popular y producen la marginación de las grandes mayorías, que no encuentran canales de expresión para sus reivindicaciones. En consecuencia, la Iglesia se siente urgida a dirigirse directamente a los oprimidos -en lugar de apelar a los opresores-' llamándolos a tomar las riendas de su propio destino, comprometiéndose a apoyarles en su reivindicaciones, dándoles oportunidad de expresarlas expresándolas ella misma." (Gutiérrez, 1984: 153).

Estos compromisos y acciones políticas transformadoras en busca de una liberación de los pobres respecto a las situaciones de opresión, sinónimo de situaciones de pecado conlleva a cambios de especial profundidad: "esa liberación pasa necesariamente por una ruptura con la situación actual por una revolución social." (Gutiérrez, 1984: 127).

La transformación social buscada puede hacer uso d medios pacíficos como los tomados por tantos sacerdote comprometidos con luchas populares, lo cual les ha costad, persecución, condena y hasta la pérdida de la vida. Los h habido también aquellos que han escogido el camino violento, como única alternativa considerada viable por ellos e: las circunstancias vividas; tal vez el ejemplo más recurrid, para ilustrar esta segunda postura lo haya sido el sacerdote colombiano guerrillero, Camilo Torres. La opción violenta, como forma de lucha y compromiso con la salvación y liberación de los pobres, ha encontrado por parte de concepciones teológicas un sustento que las avala, como resulta se el caso de los planteamientos de Luis Olmedo Requena respecto a una Teología de la Violencia Revolucionaria. Para ello cita a Agustín y Santo Tomás, este último, por ejemplo "habla claramente del derecho a la insurrección armada contra el poder injusto” (Olmedo, 1981: 62). Por igual hace referencia a Pablo VI, quien en su encíclica Popolorum Progressio llegó a decir:

"Sin embargo, como es sabido, la insurrección revolucionaria, salvo en caso de tiranía evidente y prolongada que atentase gravemente a los derechos 
fundamentales de la persona y dañase peligrosamente el bien común del país engendra nuevas injusticias, introduce nuevos desequilibrios y provoca nuevas ruinas."

Ante ello el autor mencionado se pregunta: “ ¿Y no es ésta la situación que vivimos en nuestros países?", por lo que considera un derecho a la insurrección entre los pueblos latinoamericanos frente a las condiciones de injusticia social que viven, de tal forma que presenta un listado de siete punto al respecto y de entre los que extraemos lo siguiente:

"La legitimidad de la insurrección armada proviene de si es necesaria o no para erradicar la opresión e implantar la justicia. El valor supremo es el bien del pueblo, su liberación. Si para ello se hace necesaria la violencia, entonces y en la medida en que sea necesaria, es justo el usarla." (Olmedo, 1981: 69).

Aunque observa la siguiente norma: "La norma sería: tanta libertad y no violencia como sea posible, y tanta violencia como sea necesaria." (Olmedo, 1981: 69).

Por su parte, la iglesia guatemalteca y una porción de su sacerdocio se encuentran con la religiosidad popular, parte importante de la cual corresponde a la de las comunidades indígenas, contexto en el que, como ya se ha visto, se suceden una serie de acontecimientos políticos cuya causa se encuentra en las condiciones sociales inoperantes entre los sectores populares y el tratamiento dado por los gobiernos posteriores a 1954, a dichos problemas sociales. Esta conjugación abre la puerta a la participación de las concepciones de la Teología de la Liberación en Guatemala, que tendría como antecedente inmediato la transformación de una Acción Católica.

En 1969 nace COSDEGUA, organismo que aglutina a los sacerdotes diocesanos de Guatemala en vistas a una promoción integral de los sacerdotes a la vez que promoción del pueblo guatemalteco. De esta experiencia surgen centenares de catequistas, delegados de la Palabra, animadores de comunidades y promotores sociales, tareas realizadas por centros como el Instituto Católico de Capacitación de Quetzaltenango y el Centro de Desarrollo Integral d Huehuetenango. En 1976 ocurre un terremoto que agudiza los problemas ya existentes en el plano social general por lo que se emite la Carta Pastoral Unidos en la Esperanza, por parte de la iglesia guatemalteca, y en la que se concibe la situación del país como equivalente a una situación d pecado y violencia institucionalizada, observada en la injusta distribución de la renta nacional y en la pobreza de la mayorías, tenencia desigual de la tierra, falta de respeto a la dignidad humana, derecho a la vida, entre otros señalamientos, lo que hace a la Iglesia tomar la opción preferencial por los pobres, actitud a la que invitan sea compartida por otra Iglesias para unir fuerzas. Para estos mo- 
mentos ya se había instalado el ambiente de terror originado por la actitud, represiva gubernamental, la Iglesia Católica, entonces, pasaba a formar parte de los objetivos del terror; es así que se da una primera muerte en la persona de un sacerdote: el padre Guillermo Woods de la Congregación Maryknoll ocurrid en un sospechosos accidente aéreo (Valdés, 1985).

Cuando sucede la masacre de Panzós, en 1978, sectores de la Iglesia Católica reaccionan conjuntamente con otra agrupaciones que manifiestan su protesta en contra de la masacre, lo que indica la participación política inscrita el movilizaciones masivas. Ese mismo año se funda el Comité Pro Justicia y $\mathrm{Paz}$, integrado por cristianos laicos, sacerdotes, religiosos y religiosas católicos, además de protestantes lo cual responde a una tendencia ecuménica, de encuentro entre cristianos pertenecientes a distintas iglesias.

Entre 1978 y 1982 -gobierno de Lucas García- la represión se extiende a miembros de la Iglesia, incluidos catequistas y delegados de la Palabra, cobrando víctimas mortales y forzando a otros a salir del país. Es durante este periodo cuando ocurre la masacre en la Embajada de España, de lo 39 muertos, tres eran catequistas. Para 1981 se estimaba que 167 agentes de pastoral (entre sacerdotes y religiosos) habían sido asesinados u hostigados hasta forzarlos a dejar el país.

Durante el gobierno de Ríos Montt, 1982-1983, se inició un diálogo entre la Iglesia y el gobierno, pero las expectativas alentadas por la iglesia se vieron frustradas ante un patente incremento de las acciones represivas al cual la misma iglesia guatemalteca califica ya de "genocidio". En 1983 el Papa Juan Pablo II visita Guatemala, "dentro de un marco oficial muy frío y de mucha tensión (Valdés, 1985: 13); una semana antes de la visita papal, son fusilados 6 jóvenes a pesar de la petición de clemencia presentada por el Sumo Pontífice. Durante su estancia en Guatemala aborda los casos de represión e injusticia vivida en la nación, asimismo trata la situación social sufrida entre la población indígena, ante lo cual, dice el Papa, la Iglesia debe "elevar su voz de condena cuando se viole vuestra dignidad de seres humanos e hijos de Dios". Importantes porciones de la Iglesia Católica, junto con sectores protestantes en una pos- tura ecuménica, habían tomado una clara actitud religiosa de evidentes implicaciones políticas a favor y junto al pueblo guatemalteco que, para estos momentos, desarrollaba amplias acciones políticas; dentro de este pueblo se encontraban las comunidades indígenas de centenaria ascendencia, las que ahora no levantaban demandas exclusivamente nativistas sino en alianza con los sectores populares ladinos -no indígenas-, vistos desde la antigüedad colonial española como sus enemigos por definición. La represión tomaba 
por igual a indígenas que a ladinos y ministros religiosos. Esto los colocó en una misma posición que afianzaba aún más las primeras alianzas ocurridas.

Comunidad, Iglesia y Guerrilla. Colocados del mismo lado en que la represión dirigía sus acciones, miembros del clero, sectores populares ladinos e indígenas, entran en relación con las organizaciones armadas opuestas a los regí- menes militares. La misma dinámica acontecida entre finales de los setenta y principios de los ochenta hace que las agrupaciones guerrilleras tiendan a unificarse -al igual que el campesinado, las organizaciones gremiales y las comunidades étnicas- ante el proceso de polarización en la sociedad guatemalteca. Por lo tanto en enero de 1982 se difunde la Proclama Unitaria de las Organizaciones Revolucionarias firmada por la Unidad Revolucionaria Nacional Guatemalteca, (URNG), constituida por las existentes organizaciones armadas: Ejército Guerrillero de los Pobres (EGP), Fuerzas Armadas Rebeldes (FAR), Organización del Pueblo en Armas (ORPA) y el Partido Guatemalteco del Trabajo -Núcleo de Dirección Nacional- (PGT). En este documento se postula la toma del poder para instaurar un "Gobierno Revolucionario, Patriótico, Popular Y Democrático”; señala a la vez , los protagonistas de la lucha dada:

"El pueblo Guatemalteco libra hoy la más grande guerra revolucionaria de su historia. Es una guerra en la cual participan obreros y campesinos, indígenas y ladinos, católicos y evangélicos, hombres y mujeres en edad de pensar y de luchar y todos los sectores patrióticos y democráticos de nuestro Pueblo." (URNG, 1982: 2)

De entre los males acaecidos sobre Guatemala comienza por el del genocidio sufrido al que califica como "el más oprobioso de América", adjetivo que sustenta con las siguientes cifras:

"Desde 1954, año en que la reacción anticomunista y el Imperialismo norteamericano derrocaron al gobierno democrático de Jacobo Arbenz, han sido asesinados en Guatemala 83,500 ciudadanos. Sólo en el año de 1981 el número de víctimas de la represión gubernamental alcanzó la estremecedora cifra de 13,500 ciudadanos." (URNG, 1982: 2-3)

En lugar de las condiciones imperantes, la URNG se plantea como puntos de gobierno los siguientes:

"I. La revolución pondrá fin a la represión contra el pueblo y garantizará a los ciudadanos la vida y la paz, derechos supremos del ser humano.

"II. La revolución sentará las bases para solucionar las necesidades fundamentales de las grandes mayorías del pueblo, al acabar con el dominio económico y político de los grandes ricos represivos nacionales y extranjeros que gobiernan Guatemala. 
"III. La revolución garantizará la igualdad entre los indígenas y ladinos, terminando con la opresión cultural y con la discriminación.

"IV. La revolución garantizará la creación de una nueva sociedad donde en el gobierno estén representados todos los sectores patrióticos, populares y democráticos.

"V. La revolución garantizará la política de no alineamiento y de cooperación internacional que necesitan los países pobres para desarro-

llarse en el mundo de hoy, sobre la base de la autodeterminación de los pueblos".

El movimiento armado unificado de hecho se integra a una amplia tendencia unitaria nutrida por sectores antes opuestos: ladinos-indígenas, católicos-protestantes, etc. Esta tendencia se genera no sólo como reacción a la "explotación capitalista", la miseria consecuente, el "dominio extranjero", la discriminación, sino en primer lugar debido a que la represión ejercida ha llegado a puntos particularmente dramáticos, al grado de que la primera preocupación de un organismo insurrecto armado, con tradición ideológica marxista, no inicie sus objetivos con principios como el de una "distribución equitativa de la riqueza" o prometiendo un amplio reparto agrario entre el campesinado, sino que plan- tea como primer objetivo poner fin a la represión y garantizar la vida y la paz, es decir, proteger lo último que puede restar a cualquier ser humano: la vida.

La dinámica política existente durante los primeros años de los ochenta se caracteriza por atentar contra la vida misma. Frente a ello las contradicciones de la sociedad se neutralizan, se entiende entonces la unión entre indígenas, ladinos, católicos, protestantes. Era la Vida la que ahora se ponía en peligro.

\section{Estrategia de tierra arrasada: el éxodo.}

Situación general de Guatemala. Durante el transcurso de los acontecimientos reseñados, la República de Guatemala, contaba con una superficie de $108.890 \mathrm{~km} .2 Y$ una población estimada, para 1984, en 8 millones de habitantes; el producto interno bruto había bajado de 1,151 dólares en 1981, al, 134 dólares en 1982; para este mismo año, se calculaba en 66.7 hab $/ \mathrm{km} 2$ como densidad demográfica, a la porción asentada en la urbe correspondía el 39\%, mientras que a la rural el $61 \%$ restante; su población menor a los 15 años de edad equivalía a 44\%; el promedio de hijos era de 5.7 por mujer, en tanto que la tasa de mortalidad infantil ascendía a 65.9\% y la esperanza de vida alcanzaba los 59 años de edad (BIO EFE, 1985). 
La tasa de desempleo, en 1983 era de $8 \%$; la tasa de subempleo alcanzaba el 33.7\%. Las contribuciones al PIB por sectores en 1982, arrojaba las cifras siguientes: agricultura, $25.4 \%$; industria, $21.2 \%$; $y$, servicios, $53.4 \%$. Las actividades agrícolas resultan las más sobresalientes en la medida en que aportan sobre el 60\% de las exportaciones; los cultivos principales son: algodón, azúcar, cacao, café, habichuelas, maíz, plátano y sorgo, según datos correspondientes a 1982 (BIO EFE, 1985).

La división territorial se compone de 22 departamentos, que a su vez aglutinan a municipios, dichos departamentos son: Alta Verapaz, Baja Verapaz, Chimaltenango, Chiquimula, El fetén, El Progreso, El Quiché, Escuintla, Guatemala, Huehuetenango, lzabal, Jalapa, Jutiapa, Quetzaltenango, Retalhuleu, Sacatepéquez, San Marcos, Santa Rosa, Sololá, Suchitepéquez, Totonicapán $y$ Zacapa.

Del total de su población, una parte importante corresponde a la porción indígena de los habitantes en Guatemala -aunque por igual se encuentra integrados a las urbes a través del proceso del trabajo migratorio entre el campo $y$ la ciudad- asentados, como ya se ha visto, históricamente en comunidades rurales campesinas. Este hecho conforma para las décadas recientes un mapa étnico del cual se puede hacer un acercamiento por medio del mapa lingüístico resultante. Se calcula que la población indígena asciende a la mitad del total nacional, por ejemplo, Alfonso Villa Rojas habla de un 45\% (Villa Rojas, 1986:161), en tanto que Yolanda Lastra cita la cantidad de 54\% para 1950 (Lastra, 1986:143); y por su parte, Arturo Valdés Oliva menciona que, en 1964, de una población total de cuatro millones, "debe tenerse como dato seguro que tres de esos cuatro millones hablan en las lenguas indígenas..." (Valdés, 1965: 9). Dicha población practica 23 lenguas indígenas diferentes (Tujab, 1987 y Lastra, 1986), de las que, por su parte, Valdés menciona que se corresponden a los grupos lingüísticos quiché, mam, pocomam, chol, maya y caribe y a los cuales corresponden los siguientes conjuntos de lenguas (Valdés, 1965: 10).

Masacres sobre poblaciones indigenas y ladinas. De entre las primeras masacre $s$ de este periodo de incremento en las acciones políticas de masas y militares, llevadas a cabo por las organizaciones populares y guerrilleras respectiva- mente, se pueden contar las sucedidas, en primer lugar, en mayo de 1978 en Panzós, correspondiente al departamento de Alta Verapaz; en aquella ocasión alrededor de 130 campesinos (Valdés, 1985) perdieron la vida a manos del ejército y finqueros que abrieron fuego sobre mujeres, niños y hombres que se habían concentrado en la plaza del lugar (Manz, 1986). Posteriormente ocurrieron en los municipios de Chajul, Nebaj y Uspantán, pertenecientes al Departamento de El Quiché, masacres que dan pie a la toma de la Embajada española precisamente, en 1980. 
Hasta este momento la represión, sin embargo, se había centrado contra personas destacadas en las acciones de oposición popular. Pero a finales de 1981, bajo el gobierno de Ríos Montt, el ejército inicia una campaña de 18 meses con la finalidad de "destruir las conexiones entre la oposición armada y cualquier real o imaginaria base de apoyo para ésta” (Manz, 1986: 32). Entonces el ataque se dirigió tanto contra las columnas guerrilleras como contra las aldeas comprendidas en las zonas de influencia de los grupos armados insurrectos. Este cambio de objetivo de la represión ejercida por el gobierno de ese momento, respondía a que, iniciada la década de los ochenta, la guerrilla contaba con respaldo popular, al grado de que se "estima que un cuarto de millón de personas en las áreas rurales apoyaban a las guerrillas realizando acciones que iban desde suministrarles alimento $\mathrm{Y}$ refugio hasta servir como mensajeros en una red de comunicaciones" (Manz, 1986: 32). De entre las zonas en conflicto destacó el actuar del ejército sobre la región indígena del Altiplano, en donde el EGP mantenía una amplia influencia existiendo condiciones casi insurreccionales, según estima Beatriz Manz.

El objetivo, a decir de los militares, era el de "quitarle el agua al pez", es decir, retirar físicamente a las poblaciones que ofrecían apoyo las organizaciones guerrilleras: comunidades que eran el agua gracias a la cual vivían los peces, es decir, la guerrilla; además éstas nutrían sus filas armadas con miembros de esas mismas comunidades, hecho que implicaba un acercamiento político y práctico en vistas a deshacerse del gobierno militar y grupos sociales dominantes. Ante tal crecimiento cualitativo y cuantitativo del movimiento opositor -que rayaba en la insurrección-, el ejército implementó una especial estrategia cuya finalidad intentaba retirarle a la guerrilla las comunidades -rurales campesinas, por igual ladinas e indígenas-, dicha estrategia fue conocida como politica de tierra arrasada (Arias, 1984); estrategia que la diversa bibliografía sobre el caso, menciona como impulsada por asesores estadounidenses que ya la habían ensayado, antes de su derrota, en la sangrienta guerra de Vietnam (González Janzen, 1975). Las masacres, entonces, se incrementan en el número de aldeas afectadas y cantidad de personas muertas, a la vez que en el grado de crueldad puesto en práctica por los cuerpos militares.

Debido a que las tareas, ahora asignadas a los miembros de las fuerzas armadas institucionales del país, adquirirían un muy especial carácter, los entrenamientos no sólo físicos sino por igual intelectuales tomaron un sentido también muy particular. Un ejemplo de ello nos lo da el siguiente relato, sobre el grupo especial de contrainsurgencia llamado Kaibiles -tigres, en lengua quiché-: 
"El capitán, como un energúmeno, preguntaba a gritos a un batallón:

- ¿Qué come un kaibil?

- Caarnee... contestaban al unísono, como poseídos, inscrita su mente en el cuadro de la muerte, aquellos seres que en esos momentos no eran humanos.

- ¿Qué clase de caaarnee...? -volvía a preguntar, casi fuera de sí el oficial.

- Humanaaaa... -respondían más de 400 enajenados.

Y el capitán insistía:

- Qué tipo de caarneeee humanaaa...?

- Comunistaaa... -respondía la tropa, tropa que, al concluir la última a de comunista, emitía sonidos extraños; no eran gritos sino más bien aullidos.

La demencia colectiva fue interrumpida por una nueva pregunta del capitán:

- ¿Qué bebe un kaibil?

-Sangreee... -respondían aquellas bestias con los rostros descompuestos.

Y de nuevo el grito-pregunta:

- ¿Qué clase de sangre...?

-Humanaaa... -contestaban los kaibiles, acentuándose cada vez más su identificación con las fieras del Petén.

- Qué tipo de sangre humana?

- Comunistaaa... “(Mondragón, 1983: 34-5).

Con este relato podemos acercamos a la caracterización de la violencia ejercida en la práctica por estos cuerpos especiales, quienes desde las acciones de tierra arrasada provocaron la muerte de numerosos seres humanos entre niños, ancianos, mujeres y hombres adultos, además de la quema de cosechas y sembradío s, rociándoles sustancias tóxicas, se envenenan las fuentes de agua así como la comida, se aniquila a los animales criados dentro de la economía doméstica campesina, se destruyen las casas, plazas escuelas, talleres y templos religiosos; es decir, la eliminación completa de las unidades comunitarias campesinas, la destrucción de los complejos económicos, culturales y físicos integrantes de la vida de las aldeas indígenas y no indígenas. La destrucción de todo, de la Vida misma.

El Comité Pro Justicia y Paz en Guatemala realizado una serie de recopilaciones sobre casos, tanto de masacres como, en lo general, de violaciones a los derechos humanos en este país de América Central. De los varios 
Convergencia Revista de Ciencias Sociales, núm. 12/13, 1996, Universidad Autónoma del Estado de México

documentos que hacen un registro anual sobre el asunto, es que se citan, a continuación, algunos, solo algunos, de los casos concretos de masacre $s$ efectuados sobre comunidades y entre los que se mencionan implicaciones religiosas.

Caso No. 9, 16 de noviembre de 1982. Aldea: La Libertad, Municipio: Los amates, Departamento: Izabal

"[...] La iglesia fue desmantelada por los comisionados militares quienes también destruyeron los hogares de las personas que huyeron y les robaron sus animales..." (CPJyPG, 1982: 38).

Caso No. 19, Cantón: Chupol, 30 de marzo de 1982

\section{Municipio: Chichicastenango. Departamento: El Quiché}

"El 30 de marzo, la gente estaba en la iglesia evangélica orando al Señor cuando entró el ejército y les preguntó que porqué estaban reunidos. Ellos contestaron que 'para orar al Señor', pero el ejército los acusó de ser guerrilleros y les tiró granadas. Una persona pudo escapar, pero murieron 36, entre hombres mujeres y niños. Había un niño de 7 años que quedó vivo entre todos los muertos. El nos contó lo que había pasado después de que el ejército se retiró y entonces fuimos al lugar a ver lo que había pasado. Ese mismo día en Chucalibal mataron como a 46 personas. Chucalibal está como a 13 kilómetro de Chupol. El ejército, vestido con uniformes manchados, llegó y ametralló las casas y a la gente que estaba trabajando en los maizales. Mi tía estaba en su casa haciendo la comida para la familia. su esposos y un hijo ya se habían ido por miedo al ejército. Ella se quedó por que pensó que no le harían nada a ella y a los niños, pero el ejército llegó y les tiró una granada y todos murieron. Al niño más pequeño lo estrangularon. Mi tía estaba embarazada como de 7 meses. Los niños tenían 10, 8, 6, 4 y 2 años. También quemaron 14 casas, la ropa y algunos cerdos. (CPJyPG, 1982: 59).

\section{Caso No. 21, Mediados de abril, Municipio: La Libertad, Departamento: El} Fetén

La masacre ocurrió a las 11 de la noche. El ejército entró con tanques a bombardear la población y quemar las casas. La gente se levantó y salió corriendo de sus casas medio dormidos. Fueron ametrallados. A los niños que encontraron dentro de las casas, los agarraron de los pies y los estrellaron contra los postes de las casas, hasta matarlos. Los soldados violaron a las niñas. Terminaron completamente con la población en donde vivían más de 170 familias. (CPJyPG, 1982: 60). 


\section{Caso No. 23, 15 de junio de 1982, Departamento: Huehuetenango}

Soldados que el testigo había visto previamente, llegaron en camiones y rodearon la aldea. Ellos dijeron que toda la gente de la aldea eran guerrilleros, aún las mujeres y los niños. El testigo corrió y se escondió, entonces vio como los soldados mataban a 15 personas, a machetazos, incluyendo mujeres. Le prendieron fuego a las casas, y en algunas ocasiones abrían las puertas de los ranchos y tiraban granadas dentro. En total, mataron como a 50 personas y otras 50 en la aldea vecina que también fue quemada. Dos de los muertos, eran tíos de testigos. A un kilómetro de distancia, el testigo vio a mujeres de la aldea que estaban colgadas de los pies, sin ropa. (CPJyPG, 1982: 60).

La constante existencia de un sobreviviente después de las masacres ha hecho pensar que formaba parte del cuadro represivo, ya que dicho sobreviviente iba a otras aldea, buscando refugio, y comentaba lo visto por él, hecho que transmitía miedo a los habitantes de las aldeas vecinas, generando un estado de terror, pánico que tenía funciones contrainsurgentes en la medida en que asociaba la enfermiza violencia de los cuerpos especiales aplicada a aquellos sobre los que se tuviera, cierta o no, la más remota sospecha de mantener conexiones con la guerrilla. Es en este sentido que pueden dimensionarse y "comprenderse" las causas de comportamientos como los siguientes:

Caso No. 29,18 de julio de 1982, Aldeas: Concul, Raxjut y Plan de Sánchez, Municipio: Rabinal, Departamento: Baja Verapaz

[...] Cuando ella trató de defenderse diciendo que no había hecho nada y que venía a la iglesia donde cantaba en el coro, los soldados la pusieron ya gravemente herida, encima de los cadáveres carbonizados, para burlarse de ella, pidiendo que su Dios la salvara a ella y a los muertos. Horas después fue encontrada allá por su papá quien la trajo al pueblo para salvarla. Los soldados se enteraron y le dijeron: "si quieres salvar a tu hija, tienes que morir tú". Los soldados querían pegarle fuego a la muchacha, porque era testigo. Por las súplicas del papá no lo hicieron. Pocos días después murió la muchacha. [..] (CPJyPG, 1982: 64).

En otra fuente se menciona el siguiente relato:

Llegaron los pintos al poblado, encerraron a todos los hombres en la iglesia, les pusieron una bolsa de plástico en la cabeza, amarrada al cuello. La bolsa estaba llena de cal. Agarraron a los patojitos [niños pequeños] y los aventaron al aire, y les dispararon como si fueran pajaritos.

Los pintos agarraron a unos hombres, les cortaron la nariz, las orejas y la barba, y los dejaron sangrando. $Y$ les hicieron ir por todas las comunidades, para asustar a la gente.

El esposo de María había organizado nuestra cooperativa. Ella estaba en estado. Llegaron los pintos y le cortaron la cabeza a su esposo. Ella lloraba y gritaba mucho. 
Convergencia Revista de Ciencias Sociales, núm. 12/13, 1996, Universidad Autónoma del Estado de México

Entonces le abrieron la panza, le sacaron al niño, metieron la cabeza de su esposo y la volvieron a coser.

Ellos dijeron que mi compadre era de la guerrilla y le cortaron los huevos.

Los pintos están matando a nuestra gente así nomás porque sí." (Mondragón, 1983: 36).

Llegaron y nos formaron a todos. Llamaron a dos compañeras y las acusaron de subversivas. Les hicieron prender un fuego. Entonces tomaron a uno, entre varios, y le abrieron el pecho y le arrancaron el corazón. Lo echaron al fuego y se lo comieron. Al otro le abrieron el pecho y metían allí sus tortillas para que se llenaran de sangre. Y se las comían enfrente de todos nosotros. (Mondragón, 1983: 37).

Aquellas preguntas del oficial a sus fuerzas kaibiles no eran puro entrenamiento ideológico, era un entrenamiento para la acción concreta.

Los resultados fueron masivos: cerca de 400 comunidades destruidas y entre 50,000 y 75,000 personas asesinadas entre 1978 y 1984 (Manz, 1986: 33); sobre un cálculo de 7.2 millones de habitantes para esas fechas, se ha estimado que un millón aproximadamente, fue desplazado de su lugar original, de tal manera que uno de cada siete guatemaltecos se encontraba desarraigado (CPJyPG, 1982); desarraigo que podía ser vivido todavía en grupo -junto a otros familiares o paisanos- o solos, viudas, huérfanos lanzados a lugares ajenos. Las regiones étnicas fueron las más afectadas por tales medidas, situación que ha hecho concluir a diversos observadores y organismos que no sólo se cometió un genocidio sino un etnocidio, ambos actos que remiten la memoria al terror nazi durante la segunda Guerra Mundial, en donde no únicamente se asesinó a la población judía en los campos de exterminio, sino, por igual se arrasaron poblaciones enteras al ser bombardeadas. Las atrocidades nazis y el negro capítulo de Viet Nam compartirán las historias vergonzantes del presente siglo junto a lo sucedido en la Guatemala reciente.

La estrategia de tierra arrasada tiene una parte complementaria, la alde modelo y los polos de desarrollo, asentamientos nuevos o instalados sobre los restos de comunidades desbastadas, pero cuya composición es heterogénea en lo étnico, municipal y regional, lo cual rompe con instancias organizativas que resultan contrarias a las intenciones de la contrainsurgencia; a la vez, cuenta con una presencia que antes era casi ausente: el ejército, bajo su control están prácticamente estos nuevos conglomerados poblacionales, y sumado a ello se encuentran las llamadas patrullas de autodefensa que, integradas por los mismos campesinos habitantes de dichas aldeas, tienen por misión realizar patrullajes en busca de columnas guerrilleras, en una acción de autodefensa. Estas medidas neutralizan de por sí cualquier posibilidad de reconexión orgánica con las agrupaciones opositoras armadas. 
Pero las comunidades restantes y los trozos dispersos de aquellas poblaciones arrasadas, se han negado a morir como tales, en un afán de vida elaboraron también sus estrategias, de las cuales se pueden distinguir tres alternativas: la formación de comunidades de población en resistencia y los campamentos de refugiados; los primeros se mantienen aun en territorio guatemalteco mientras que los segundos han encontrado lugar traspasando las fronteras de lado mexicano.

Las comunidades en resistencia han dirigido su camino hacia las montañas en la región del Ixcán, entre los departamentos de Huehuetenango y El Quiché, son grupos de hombres, mujeres, niños y ancianos, que conservando sus formas de organización familiar y comunitaria se incorporan a otros grupos en las mismas condiciones para refugiarse en el monte, evadiendo al ejército y de esta manera, hacerse de un espacio para vivir.

Por su parte, la porción de refugiados dirigió su camino a territorio mexicano, al estado de Chiapas, entidad federativa mexicana no extraña a su historia lejana (región de pueblos de lenguas mayenses), ni a la inmediata: el Soconusco, región de plantaciones, ha sido lugar en donde se contratan para las cosechas, entre otros cultivos, del café, así que anduvieron veredas ya hechas y llegaron a encontrarse con rostros no tan desconocidos. Por su parte, la población mexicana, particularmente la campesina que habita cerca de la línea fronteriza con Guatemala, les ofreció ayuda material, económica y de albergue en solares pertenecientes a las rancherías chiapanecas, en esta labor también ha colaborado la Diócesis de San Cristóbal las Casas.

El proceso de tierra arrasada y su consecuente desplaza- miento de poblados ha implicado una dispersión al interior de las unidades comunitarias, entendidas éstas en los niveles de municipio y aldea. La desaparición física de una comunidad no significó precisamente la muerte del total de sus moradores, los sobrevivientes, o tomaron la alternativa de conformar una comunidad en resistencia, o bien, integrarse a un campamento de refugiados; sin embargo, estas opciones significaron la disgregación física y espacial de sus comunidades de origen e incluso el desmembramiento de unidades familiares, con lo que se desintegraron los sistemas sociales locales: mutilación de un cuerpo, o, en otra figura, como haber arrancado de cuajo un árbol y regar sus ramas, hojas y tronco por distintos lugares; unas comunidades resultaron no tan desintegradas, mientras que otras fueron dispersadas espacialmente de una manera por demás numerosa.

Una aproximación la mutilación de las comunidades en su nivel municipal, la ofrecen las siguientes cantidades correspondientes a los habitantes de los campamentos, según municipio guatemalteco de origen: Barillas, en 20 
campamentos; Colotenango, en 4; Concepción, en 5; Chiantla, en 1; Jacaltenango, en 16; La Democracia, en 5; Nentón, en 21; Santa Ana Huista, en 32; San Antonio Huista, en 11; San Mateo Ixtatán, en 17; San Miguel Acatán, en 10; San Pedro Necta, en 3; San Rafael la Independencia, en 3; y, San Sebastián Coatán, en 2 (cantidades basadas en datos de la Comisión Mexicana de Ayuda a Refugiados). En ellas es posible apreciar la dispersión por municipio -de los correspondientes al Departamento de Huehuetenango- y el posterior desplazamiento de miembros de los mismos a campamentos instalados en Chiapas. De los municipios referidos, destaca el caso de Santa Ana Huixta, el cual quedó desmembrado, en relación tan sólo a los reasentamientos ubicados en Chiapas, en 32 campamentos, esto sin tomar en cuenta al resto del municipio que pudo haberse mantenido en su lugar de origen, más aquellos dispersos en comunidades en resistencia y otros que puedan vivir en sitios aun no registrados.

El gobierno mexicano ha respondido a la presencia de la población refugiada por medio de la Comisión Mexicana de Ayuda a Refugiados (COMAR), organismo interinstitucional formado por las secretarias de Gobernación, Relaciones Exteriores y del Trabajo y Previsión Social, la que coordina asistencia en rubros como salud, y alimentación. A este organismo se suma el Alto Comisionado de las Naciones Unidas para los Refugiados (ACNUR), quien tiene oficinas en la región -en Comitán, en el estado de Chiapas. Sin embargo, los campamentos guardan un amplio margen de autonomía en lo orgánico, lo cual les permite discernir respecto al tipo y la forma de ayuda que reciben. Hacia 1984 se estimaba que alrededor de 46,000 personas habían pasado a territorio mexicano, habiéndose iniciado el flujo a un ritmo de 400 personas por semana en 1982 (COMA, 1988). Otros cálculos hablan de cantidades mayo- res que llegan hasta los 200,000 y 300,000 refugiados (CERI-GUA, 1988). Con todo, el organismo mexicano de asistencia a la población refugiada mantiene en mayor o menor medida, asistencia sobre tres partes: Chiapas, Cam- peche y Quintana Roo, en donde, según datos para 1988 (COMAR, 1988), había un total de 68 campamentos: 64, 2 Y 2, respectivamente. Sin embargo, estas cifras han variado, en tanto que ocurre que un campamento se divida en otros dos o más, de tal suerte que en 1989 se hablaba de más de cien campamentos en Chiapas extendidos por los municipios chiapanecos de Trinitaria, Comalapa y Margaritas. Para diciembre del mismo año en Quintana Roo había 7,301 personas; en Campeche 11,055 personas; y, en Chiapas 22,811 personas.

Debido a acuerdos bilaterales, entre los gobiernos de México y Guatemala, se tiene la política de promover la repatriación de la población refugiada 
ante lo cual éstos han tomado posturas diferentes, unos a favor de volver a su país por medio de este programa y otros que muestran desconfianza al respecto y prefieren mantenerse en los campamentos. Los primeros son los menos; su vuelta a Guatemala no resta importancia ni numérica ni cualitativa al asunto, ya que así como dejan México nacen niños de padres refugiados, por ejemplo, conforme a datos de la Subdirección Campeche de COMAR, entre 1984 y 1989, se repatriaron 2408 personas, en ese mismo lapso nacieron 2805 niños: un incremento de 307 personas más en a la población refugiada a pesar de las repatriaciones.

Conforme a lo conocido directamente en visitas a algunos campamentos instalados en Chiapas, fue posible observar una fuerte integración que en una primera impresión puede ser entendida en tres niveles: nacional, lingüística y municipal. Sin que esta división pretenda ser categórica, permite considerar que la población refugiada, si bien mantiene relaciones fraternales con los habitantes mexicanos chiapanecos, deslinda su adscripción nacional dentro de una identidad guatemalteca, lo que implica la existencia de fuertes expectativas de regreso a su patria, pero en condiciones que una buena parte de ellos, considera aun no existen en su país, como lo demuestra la escasa porción repatriada y una serie de documentos en que manifiestan su postura, citemos, de uno de ellos, algunos párrafos:

“[...] Queremos también que sepan que el principal anhelo del pueblo refugiado es poder regresar a nuestra patria, pero para poder lograr esto hemos hecho un planteamiento al señor presidente Vinicio Cerezo, el cual está contenido en las siguientes cinco condiciones:

1. Pedirnos que se nos reconozca el legítimo derecho que tenemos sobre nuestras tierras en Guatemala, las cuales nos vimos obligados a abandonar por la represión del ejército y demandamos nuestro derecho a regresar a esas tierras que legal y legítimamente nos pertenecen.

2. Que se nos asegure el derecho irrestricto de organización al regresar a nuestras tierras.

3. Que su gobierno públicamente garantice la vida de todos los que nos repatriamos (a partir de nuestra decisión libre e individual)

4. Que en el territorio donde nosotros nos ubicamos en Guatemala -(nuestras tierras) existan solamente instituciones y autoridades civiles del gobierno, excluyendo la presencia del ejército.

5. Quese permita que nuestro regreso estéacompañadode delegaciones gubernamentales de otros países y de organizaciones no gubernamentales..."

Firman los miembros de las Comisiones Permanentes de Representantes de los estados de Chiapas, Campeche y Quintana Roo. (SARG, 1988, 15). 
Es así que la población refugiada en México se inscribe como una parte más del complejo problema regionalizado que significa Centroamérica, en donde si bien casos como de Nicaragua y El Salvador han sido ampliamente atendidos por los medios de comunicación y académicos, no quiere decir que sean ni los únicos ni los más graves, el problema regional implica, por medio de los refugiados, por ejemplo, a México y en cuyo contexto general es por demás conocida la presencia "diluida" de los Estados Unidos de Norteamérica.

\section{El caso de un municipio}

San Miguel Acatán. Para ilustrar lo anterior abordemos un caso concreto, el del municipio de San Miguel Acatán, perteneciente al Departamento de Huehuetenango, que a su vez se integra por un total de 31 municipios; ubicado sobre la Sierra de los Cuchumatanes abarca una superficie de 24,030 has., adjudicadas en 1898. Su población en 1950 era de 10,395 habitantes, de la cual 10,228 hab. correspondían a la porción indígena, mientras que tan sólo 167 habitantes eran "ladinos", es decir, no indígenas (Recinos, 1954), esta población aumenta para 1981, según el censo correspondiente (Nolasco y Melesio, 1986) a 16,321 habitantes; la lengua indígena pertenece al Acateco, aunque, conforme a lo declarado por miembros de esta comunidad refugiada en México, su lengua es identificada bajo el nombre de Kanjobal. El municipio se integra por las siguientes aldeas: 1) Coyá, 2) Cheche, 3) Chenichan, 4) Chimbán, 5) Paiconop, 6) Poza, 7) Suntelaj, 8) Tequisislaj y 9) Yalaj. Sus caseríos: 1) Bonanchulup, 2) Canicham, 3) Camel, 4) Canuleu, 5) Copá, 6) Cozancanalaj, 7) Cutá, 8) Chaló, 9) Chachén, 10) Chenpech, 11) El Mul, 12) Incop, 13) Ixcanac, 14) Ixcapconop, 15) Ixchoch, 16) Ixcú, 17) Ixcuyarrán, 18) Ixlachoch, 19) Ixlahuitz, 20) Ixticultaj, 21 Jom, 22) Joventantelaj, 23) Joveyachap, 24) Joveyalaj, 25) Mete, 26) Najap, 27) Najaptaj, 28) Nujchoch, 29) Ocheval, 30) Pacalaj, 31) Petamchim, 32) Poquí, 33) Poj, 34) Quixic, 35) Sajchén, 36) Sequel, 37) Siomá, 38) Siquinhuitz, 39) Sisimtón, 40) Solomhuitz, 41) Sostelaj, 42) Sotolaj, 43) Talvé, 44) Taquiná, 45) Ticajá, 46) Ticxequelaj, 47) Tomsislaj, 48) Tzujanchn, 49) Xacalvé, 50) Xextelaj, 51) Xocal, 52) Yaxtuntaj, 53) Yocová, 54) Yoxaclá, 55) Yucajón, 56) Yulajá, 57) Yulhuitz, 58) Yulxaj.

Además, aparecen en los registros de la COMAR las siguientes aldeas mencionadas por población refugiada proveniente de San Miguel Acatán: Acacolla, Ixca, Ixchocho, San José, Santa Teresa y Yencop.

Por lo que respecta a los escasos antecedentes históricos localizados, Adrián Recinos nos menciona que: "En el paraje de Tenam, no lejos de San 
Miguel, se contemplan algunas ruinas indígenas que, según tradición local, corresponden a una población importante que en tiempos prehistóricos fue el centro de toda esta comarca" (Nolasco y Melesio, 1986: 351).

Por lo que toca a su economía, entre sus recursos naturales se contaban, para la década de los cincuenta: piedra de cal, y depósitos minerales -de plomo (Siegel, 1956)- en el rubro agrícola se cultivaba trigo, maíz, haba, legumbres, patatas, cheche (variedad de agave), café, caña de azúcar, banano, camote, yuca, y frutales. Estas actividades se realizaban sobre tierras cuya tenencia se encontraba dentro de un mar- cado minifundismo, del cual se puede suponer un incremento en las décadas posteriores, de acuerdo a la situación general del país. En relación a las condiciones campesinas era de esperarse que recurrieran al trabajo asalariado, realizado en fincas de la costa sur del país y de Tapachula, en el vecino país de México. Paralelamente practicaban algunas industrias insertadas en su economía doméstica campesina como era la elaboración de panela, harina, tejidos de lana (chamarras, capishayes), sombreros de palma y de paja de trigo, lazos, redes, metates, aparejos, albardas, hamacas, suyacales de palma, mantillones de lana y objetos de barro (Siegel, 1956: 349). De entre estas actividades, destaca la importancia de la industria de la costura debido a su carácter esencialmente indígena, "desarrollada por ellos mismos, sin ninguna ayuda o guía del exterior” (Siegel, 1956: 287), hecho que destaca aun más si se toma en cuenta que antes de 1944 esta industria se encontraba en manos exclusiva-, mente de ladinos. Junto a esta actividad estaba -entre las décadas de los cuarenta y cincuenta- el comercio de mercancía traída de México pasada de "contrabando", sobre ello Siegel apunta: "De sesenta a cien indígenas caminan hacia la frontera semanalmente, se escabullen entre la misma, y toman el autobús, que en una hora los lleva a la ciudad mexicana de Comitán” (Siegel, 1956: 87).

Es así que se notaba un auge económico comprendido en el periodo 1944-54-, el cual se proyectaba en el incremento del comercio: formación de un mercado "de considerables proporciones los días domingo" en la cabecera municipal y otro en Coyá los días viernes, además de establecimientos comerciales, propiedad no ya sólo de ladinos sino, y esto es lo importante, de indígenas (Siegel, 1956: 285).

Los cambios económicos registrados durante esos momentos trajeron cambios culturales en el vestido: "Ahora se miran con más frecuencia mujeres indígenas sin sus huipiles, pero, siempre lo usan los domingos y días de fiesta" (Siegel, 1956: 290); la vivienda: "Cada vez más indígenas techan sus casas con tablas” y tejas de barro, en lugar del tradicional techo de paja (Siegel, 
1956: 289). Cambios que alterarían por igual algunas pautas como el consumo de alcohol, el cual el autor atribuye a este repentino cambio económico.

Siegel nos dice que "Por primera vez, desde la conquista española, el dominio efectivo del gobierno local está en manos de los indígenas" (hacia 1950), en tanto que los principales cargos de alcalde, regidores y síndico se encuentran bajo el dominio de la población indígena y logrados por voto popular (Siegel, 1956: 284). Este acontecimiento ocurrido a mediados del presente siglo, se ha integrado a un sistema de gobierno que combina una parte civil con otra religiosa; al respecto resulta ilustrativo el esquema que ofrecen Nolasco y Melesio (1986), para los municipio hablantes de Kanjobal y entre los que incluyen a San Miguel Acatán.

Desde la concepción católica del municipio, y conforme la versión ofrecida por originarios de San Miguel Acatán actualmente residentes en un campamento de refugiados en Chiapas, este municipio se funda, hace muchos siglos atrás cuando, "según dicen los abuelos", el Arcángel San Miguel se apareció en un lugar que se llama Acatán, puso su foto en un árbol grande de ahí. A ese árbol lo tumbaron y lo llevaron adonde comenzaron a construir una iglesia formándose entonces el pueblo de San Miguel Acatán. La iglesia se construyó de "pura laja”. La imagen que ahí se venera está hecha de madera, su tamaño es en proporciones mayores a las de una persona. $\mathrm{Su}$ fiesta se celebra el 29 de septiembre. Otras celebraciones del pueblo son $\mathrm{Na}$ vidad, Semana Santa, Todos Santos, miércoles de Ceniza y Corpus Christi. El conjunto de personas encargadas de organizar las celebraciones es el Comité de la Iglesia o Senado de la Iglesia quienes organizan los cultos "junto con toda la población”. El último año en que celebraron el día de San Miguel en el municipio, estando ellos ahí, fue en 1982.

Sobre la vida religiosa en el municipio, Recinos nos dice que en el poblado se encuentra “... una iglesia antigua y convento anexo, levantados por los padres de la religión mercedaria y reconstruidos recientemente por los padres de la sociedad Maryknoll que administran la parroquia" (Recinos, 1954: 350). Esta misión religiosa católica se estableció en San Miguel Acatán a principios de 1947; su labor ha impactado notoriamente a la población en varios aspectos, Por ejemplo, en lo relativo a las pautas matrimoniales. Antes de 1949 éstos se realizaban independientemente de ceremonias civil y religiosa (católica), a partir de la presencia y trabajo de los misioneros el número de matrimonios bajo sanción legal civil y católica se incrementaron; dicho cambio se inscribía en los objetivos de la Misión de "librar a los indígenas de sus creencias y costumbres «paganas y supersticiosas», de enseñarles los fundamentos del verdadero catolicismo y, de esta manera, devolverlos en debida 
forma a la Iglesia" (Siegel, 1956: 292), desde tal postura es que el sacerdote se muestra contrario al consumo de bebidas alcohólicas y al uso excesivo de la marimba -tocada en distintas ceremonias consideradas por el complejo cultural ritual del municipio-. Ante dichas prácticas ofrece instrucción religiosa y enseña devoción fundamental a un grupo de niños del lugar.

Para los años cincuenta, misioneros protestantes llevaban viviendo en el municipio cosa de veintidós años sin haber logrado convertir a un solo indígena (Siegel, 1956: 298). Para fechas más recientes, Nolasco y Melesio (1986), mencionan que se había presentado algún conflicto entre católicos y protestantes, pero los acontecimientos de principios de los ochenta "ha restado cualquier importancia al conflicto religioso" (Nolasco y Melesio, 1986: 207).

No queremos dejar de mencionar lo que anota Recinos sobre su cabecera municipal a mediados de siglo:

Está situado en las faldas de los cerros denominados Pol y Poj, a 1,800 metros sobre el nivel del mar, en bella y agradable situación. El clima es templado y sano y la comarca fértil, bien trabajada y poblada por unos 1,250 moradores. El lugar es uno de los centros más adelantados y de más agradable vivienda en el Departamento (Recinos, 1954: 350).

Este ambiente de "agradable vivienda" que nos ilustra Recinos y el auge económico paralelo a un mayor control político indígena sobre el municipio que nos refiere Siegel, parece ser que decayeron, de alguna manera, en las décadas posteriores, ya que:

"A finales de la década de los setenta, el EGP comenzó a organizarse y hacer su presencia conocida en la municipalidad de San Mateo [Ixtatán], al principio en las aldeas de los alrededores. Mucha gente que se había ido a los proyectos de colonización en el Ixcán se unieron a las guerrillas allí y luego regresaron al área de San Mateo y San Miguel [Acatán] para hablar con sus amigos en las aldeas sobre la causa." (Manz, 1986: 111).

Si ocurrió una respuesta favorable al EGP no es difícil que se debiera al deterioro económico y político presente en el país, y compartido por el Departamento de Huehutenango, y sus municipios, incluido el de San Miguel Acatán. Esto motivó que San Miguel compartiera las masacres en contra de las comunidades indígenas.

San Miguel Acatán y sus aldeas masacradas. Entre 1981 y 1985 en Huehuetenango habían ocurrido masacres diversas realizadas en 13 de sus municipios, de un total de 31, Y que fueron: Aguacatán, Barillas, Colotenango, Concepción, Chiantla, Huehuetenango, La Democracia, Nentón, San Antonio Huixta, San Ildefonso Ixtahuacán, San Juan Ixcoy, San Mateo Ixtatán y san Miguel Acatán. A estos municipios, durante el proceso de desplaza- 
miento e instalación en campamentos en Chiapas, se sumaron habitantes de Jacaltenango, Santa Ana Huixta, Santa Eulalia, San Pedro Necta, San Rafael la Independencia y San Sebastián Coatán. Es decir, no hubo una correspondencia directa entre masacre reportada -por organismos de defensa de los derechos humanos- y proceso de desplazamiento, finalmente el pánico generalizado por lo ocurrido en las zonas de conflicto propició una huida masiva de sus lugares de origen.

En este ambiente San Miguel Acatán sufrió varios ataques por parte de las fuerzas armadas y entre los que se pueden contar los siguientes reportados:

1981

31-mayo-81

19-julio-81

17-agosto-81

20-julio-82
Santa Rosa*

más de 150 personas, en Coyá**

300 víctimas en Coyá*

15 personas, en Suntelaj**

200 víctimas*

${ }^{*}$ Comité Pro Justicia y Paz en Guatemala.

**Manz, 1986: 113

Según esta información, entre 1981 y 1982, al menos ocurrieron en el municipio cinco masacre s cuyo saldo fue de 665 víctimas, cantidad que hay que considerar en proporción a los 16,321 habitantes censados en 1981, es decir, el $0.04 \%$ de su población fue muerta, por lo menos.

Las circunstancias particulares de una parte de estas masacres han quedado reseñadas para la historia:

\section{1 de mayo de 1981}

“200 soldados atacan la aldea de Coyá, San Miguel Acatán Huehuetenango, asesinando a más de 150 personas. Los helicópteros rodean y bombardean la región, mientras que los soldados arrojan granadas y abren fuego sobre las mujeres niños y ancianos." (Manz, 1986: 11)

\section{9 de julio de 1981, Aldea: Coyá.}

"A las 6:00 a.m. tropas de Jacaltenango, en número no determinado, llegaron a la aldea Coyá y empezaron a disparar contra la población. Llevaban ametralladoras 30 y 50 Y con ellas batían a la población. Ante esta situación, los habitantes de las aldeas vecinas 
acudieron en ayuda de los pobladores, dejando solas sus respectivas aldeas. A las 7:00 a.m. penetraron por San Miguel Acatán 200 soldados en camiones particulares

"A las 7:30 a.m. llega un helicóptero y sobrevuela la aldea. La población en masa intentó embestir con palos, piedras y machetes a la fuerza del ejército procedente de Jacaltenango. Pero esta fuerza estaba atrincherada y los contenía con el fuego de las ametralladoras. La población se tendía, pero empezaron a caer los primeros. La población buscaba formas de avanzar sobre los soldados, pero siempre eran rechazados y obligados a retroceder. Entre la masa había incluso mujeres con niñitos a "tuto". Ellas avanzaban al lado de los hombres armadas como todos, de palos, piedras y machetes.

"La distancia que separaba a las dos fuerzas era de pocos metros. Los soldados gritaban vivas a Lucas. La población gritaba vivas al pueblo y a la Revolución. El enemigo insultaba. La población respondía con consignas políticas.

"A las 10:30 a.m., la fuerza enemiga había penetrado por el norte de la aldea, hasta la orilla de un río. Algunos habitantes lo detectaron y se volvieron para dejarles caer y tirarles piedras. El ejército respondía con una balacera desenfrenada, en la que mezclaba tiro graneado, ráfagas y granadas. Parece haber habido también bazzokazos. Luego, el fuego bajó.

"A las 11: 15 a.m., esta misma fuerza volvió a desencadenar otra balacera. Y mientras todo esto sucedía no había cesado el fuego de ametralladoras y fusiles contra la población de Coyá. También granadas les lanzaba el ejército.

"A las 11:50 a.m., se presenta de nuevo el helicóptero. Esta vez ametrallando a la población que trataba de contener a la fuerza del ejército que avanzaba desde el Sur. Persiste en ametrallar durante 30 minutos. A las 11:55 a.m., aparece un avión de combate AT-37B, el cual, simultáneamente al ataque del helicóptero, ametralla y bombardea a la población de Coyá. Ante el impacto de las bombas, las casas y los habitantes refugiados en ellas volaban en pedazos. También voló de esa manera la capilla en donde se había refugiado gente. La metralla del avión era mucho más feroz y efectiva que la del helicóptero.

"Para entonces ya habían caído muertos y heridos bastantes pobladores y los que quedaban en pie, aun cuando se daban cuenta de que con palos, piedras y machetes no podían contener el avance de los fusiles, ametralladoras y fuerza aérea, estaban enardecidos, decididos a morir luchando, sólo lamentaban no contar con medios para defender su aldea, sus tierras y sus familias ante el ejército de Lucas.

"Después de retirarse por unos minutos, vuelve el helicóptero a las 12:40 del medio día para seguir ametrallando.

"A las 13:10 regresa el avión AT-37B y sigue bombardeando y ametrallando; helicóptero y avión lo hacen durante media hora. Luego se retiran. A las 14:00 vuelve el helicóptero a ametrallar. 
"A las 14: 15 disminuye lo más nutrido del ataque, pero continúan los disparos y las ráfagas esporádicas durante toda la noche y parte de la mañana del 20 de julio.

"Las primeras noticias salidas de la aldea y sus alrededores reportan (al día siguiente de la masacre) cerca de 300, asesinados. La mayoría cayó en el centro de la población o amontonados en el interior de sus casas. Algunos pobladores lograron huir a las montañas de los alrededores. Luego de la matanza, los soldados del régimen de Lucas apilaron los cadáveres y los despedazaron con machete.

"Este hecho constituye un ejemplo de los cientos que tiene el pueblo guatemalteco sobre el carácter y la bestialidad del ejército "nacional". Así es como la infantería, la Artillería y la Fuerza Aérea emplean sus fuerzas. Fue una masacre planificada y ejecutada fríamente. La saña y la cobardía de las fuerzas del gobierno contra la valentía y combatividad de un pueblo desarmado dispuesto a defender su vida, su tierra y su familia.

"Versión del gobierno: El ejército descubrió y desmanteló una escuela de concientización comunista en la aldea de Coyá. El saldo es de 25 subversivos muertos.

\section{Guatemala, julio de 1981. Comisión de Propaganda: Coordinadora Cris-} tiana. Caso No. 35, CPJyPG, 1982: 65-66.17 de agosto de 1981

"Hombres armados matan a 15 personas en la aldea de Suntelaj, San Miguel Acatán, después de haberlos obligado a cavar sus propias tumbas. Las víctimas, incluyendo a tres de los hijos del alcalde fueron seleccionados de una lista de personas que habían contribuido a los fondos para la construcción de las escuelas para las aldeas." (Manz, 1986: 113).

\section{2 de julio de 1982, Aldea: Chemichán.}

"El ejército llegó el domingo por la tarde y fue a las casas a juntar a la gente, apartaron a cuatro patojos y los mataron enfrente de toda la gente. Por eso al anochecer, nos huimos de nuestra casa. No trajimos nada, excepto la ropa que tenemos puesta". (Caso No. 27; CPJyPG, 1982: 62).

\section{Aldea: Santa Rosa.}

"Vive en Santa Rosa, de la raza de San Miguel Acatán. En vista de que llegaron los del ejército matando a la gente, la primera vez pasaron matando a muchos. Entonces tuvieron que salir de sus casas para no dejarse morir, se dieron cuenta de que no sólo matan a la gente, sino que también están robando, todos los objetos de valor los pasan robando. También pasan violando a las mujeres, los niños son indefensos, no pueden 
correrse y los pasan matando, no los matan a balazos sino simplemente degollados. Una semana estuvieron en el monte aguantando hambre sin comida, por salir huyendo antes de que llegaran los soldados y se quedaron en el monte y allí estuvieron sin comer y se vinieron por puros caminitos extravíos; en caminado entre espinas, algunos con carguitas y otros sin nada por que todo se les quemó. y estuvieron tirando bombas en las casas, también matando gentes en muchas partes, por eso salieron huyendo. Es más, quemaron todo lo que es comestible, maíz, frijol y todo. Lo más importante es la comida, quemaron todos los ranchos. Toda la gente esta aquí viviendo en la montaña, y qué comer no traen, de vez en cuando, comen caracol, hierba, tortillita con sal, así nomás la van pasando." (Caso No. 3; CPJyPG, 1982: 71).

Como resultado de las masacre s, se repiten los desplazamientos, a este respecto los campamentos en Chiapas nos ofrecen una visión -parcial- de la dispersión generada ante las masacres, como lo muestran las siguientes correlaciones entre aldea y caserío de origen y campamento de residencia en Chiapas:

\section{Aldea}

1.- Coyá Elena

2.- Chenicham:

3.- Chimbaná: Colonia

4.- Paiconop:

5.- Poza:

6.- Yalaj:

COMAR, 1987

\section{Campamentos}

Cieneguitas, Pacayalito I, Santa El Lagartero

Cieneguitas, La Gloria

Cieneguitas, La Gloria, Chicharras

Cieneguitas

La Gloria, Chicharras Colonia

La Gloria

\section{Aldea}

1.- Incop

2.- Contzancala

3.- Solomhuitz

4.- Taquiná

5.- Xocol

6.- Yulxaj

\section{Campamentos}

Cieneguitas

La Gloria

Cieneguitas

Pacayalito I, Pacayalito II

Cieneguitas

La Gloria

COMAR, 1987. 
Aldea

1.- Aacacolla

2.- Ixca

3.- Ixchuchu

4.- San José

5.- Santa Teresa

6.- Yencop

COMAR, 1987.

\section{Campamentos}

Pacayalito II

La Gloria

Cieneguitas

Cieneguitas

Cieneguitas

Cieneguitas

Por medio de los listados anteriores se puede apreciar la dispersión generada y su posterior asentamiento en los campamentos, en las cantidades que lo muestra el siguiente listado:

\section{Campamento}

1. Amatitlán

2. Francisco I. Madero

3.Cieneguitas

4. José María Morelos

5.La Gloria

6. Chicharras Colonia

7. Chicharras Guadalupe

8. Victoria III

9. Pacayalito I

10. Pacayalito II

11. Santa Elena

12. Lagartero

TOTAL

COMAR, 1987.

\section{Personas}

10

$\mathrm{s} / \mathrm{d}$

994

9

821

32

s/d

35

10

10

s/d

21

1942

Partiendo de tales datos, ocurre que, aproximadamente " -ya que hay que descontar a los nacidos en territorio mexicano después de que sus padres emigraron del municipio-, 1942 habitantes originarios del municipio de San 
Miguel Acatán fueron desplazados a partir de las masacres ocurridas. A esta cantidad hay que sumar las 665 víctimas de las masacres, lo que da un total de 2,607 personas restadas a la población perteneciente a el municipio, lo cual significa que del total registrado en 1981, al menos el 16\% de sus habitantes originarios fueron expulsados de su lugar de residencia histórica, heredada desde la Colonia o, más aun como lo evidencia la existencia de un sitio arqueológico, anterior a la llegada de los conquistadores españoles. Es decir, una parte de la población acateca fue desarraigada de su asentamiento centenario, con lo que más de, posiblemente, 500 años de historia y cultura fueron desarticulados y dispersa- dos, al menos, entre doce campamentos ubicados en un país, si bien conocido de ellos, finalmente ajeno a su condición de guatemaltecos y sanmiguelinos.

\section{Conclusiones}

Cada sociedad construye un proyecto de ser a partir de sus parámetros históricos y culturales, el grado de consenso para dicho proyecto depende de la homogeneidad que guarden entre sí los miembros de tal sociedad. En los tiempos actuales, la diversidad existente y la amplia interacción mundial llevan más hacia la heterogeneidad, la confrontación y el enfrentamiento de proyectos distintos y antagónicos. América Latina ha vivido esto en forma constante, sus utopías son elaboradas con materia sincrética, es decir, síntesis de influencias externas que no la niegan, por el contra- rio, sus pueblos tienen la habilidad de refuncionalizar las influencias externas en relación directa con su estructura propia: ya sea invadida o abriendo sus puertas al exterior por su voluntad, el resultado es una forma nueva y distinta pero con una plataforma esencial de origen. Las sociedades latinoamericanas se modifican pero sin dejar de ser ellas mismas.

La violencia sufrida en Guatemala no ha significado la desaparición de los pueblos que constituyen este país, aun en el exilio su identidad nacional pervive de la mano de sus adscripciones étnicas. Su historia inmediata se compone de influencias y experiencias variadas que retornan filosofías que van del legado prehispánico, a pensamientos políticos de origen occidental, para con ello, armar una acción que posibilite su sobrevivencia ante contingencias económicas, políticas e inclusive militares.

Paradójicamente, a la vez que la cohesión social por factores étnicos y nacionales se mantiene, la experiencia guatemalteca da otra enseñanza: la posibilidad de que la antigua división entre indígenas y mestizos se borre. Los campamentos de refugiados en México muestran imágenes donde el ladino y 
el indio comparten la tierra, el techo y el alimento; por igual, las diferencias religiosas entre protestantes y católicos -que han costado incluso sangre entre cristianos- se detienen para abrir espacios en los que unos y otros conviven ecuménicamente.

Guatemala nos muestra descamadamente la disyuntiva entre proyectos de muerte y proyectos de vida, entre el terror de la guerra y los anhelos de justicia y paz. Pero también nos enseña cómo la condición humana -tal vez última y esencial-, ante la presencia de la muerte anula las divisiones étnicas y religiosas; estos límites en que al llegar a la orilla del barranco todos juntan sus pies sobre la tierra para no caer al vacío y alzan las manos para alcanzar un futuro donde lo que se derrame sea la vida.

\section{Bibliografía}

Aguilera Peralta, Gabriel, 1981: "La violencia en Guatemala”, en: Historia y Sociedad, número 24, México.

Arias, Arturo, 1984: "Cultura popular, culturas indígenas, genocidio y etnocidio en Guatemala”, en: La cuestión étnico-nacional en América Latina. Reimpresiones de Antropología Americana, México: Instituto Panamericano de Geografía e Historia. BIO EFE

Arias, Arturo, 1987: Guatemala. Nuestro Mundo, '85/'86, Madrid: Banco de Información EFE, Agencia EFE, Espasa Calpe.

Boff, Leonardo, 1982: “Liberación como teoría o como acción práctica?”, en: Teología de la liberación. Documentos sobre una polémica, Santander: Sal Terrae

CERI-GUA, 1987: Las sectas fundamentalistas y la contrainsurgencia en Guatemala. (Marzo), México: Centro Exterior de Reportes Informativos sobre Guatemala, Servicio Especial.

CERI-GUA, 1988: Refugiados guatemaltecos: "sin nuestra participación no habrá solución justa ni posible. Vol. II, mayo. México: Centro Exterior de Reportes Informativos sobre Guatemala, Servicio Especial.

COMAR, 1987: Análisis demográfico por campamento, marzo 87, México: Comisión Mexicana de Ayuda a Refugiados.

COMAR, 1988: Los refugiados guatemaltecos en México. Memoria de la Comisión Mexicana de Ayuda a Refugiados (1982-1988). México: Secretaria de Gobernación, Secretaría de Relaciones Exteriores, Secretaría del Trabajo y Previsión Social.

CPJyPG, 1982: Situación de los derechos humanos en Guatemala. Guatemala: Comité Pro-Justicia y Paz en Guatemala (en colaboración con el Consejo Mundial de Iglesias). 
EFCCEO-CIDA, 1971: Tenencia de la tierra y desarrollo socioeconómico del sector agrícola en Guatemala, Guatemala: Editorial Universitaria.

Fernández y Fernández, José Manuel, 1988: "El Comité de Unidad Campesina: origen y desarrollo" en Cuadernos No. 2. Guatemala/Madrid: Centro de Estudios Rurales Centroamericanos.

González Janzen, Ignacio, 1975: Esto pasó en Vietnam. México: Extemporáneos.

Guerra Borges, Alfredo, 1987: "Guatemala: tres tiempos de una historia inconclusa”, en: Centroamérica: una historia sin retoque. México: Instituto de Investigaciones Económicas, UNAM/El Día.

Gutiérrez, Gustavo, 1987: Teología de la liberación Perspectivas. Lima: Centro de Estudios y Publicaciones.

Lastra, Yolanda, 1986: "Las lenguas indígenas de Guatemala”, en: Miguel Messmacher, Santiago Genovés y Margarita Nolasco (et.a/.), Dinámica maya. Los refugiados guatemaltecos, México: FCE.

Manz, Beatriz, 1986: Guatemala: cambios en la comunidad, desplazamientos y repatriación, México: Praxis.

Mondragón, Rafael, 1983: De indios y cristianos en Guatemala, México: Claves Latinoamericanas, COPEC, CECOPE.

Nolasco, Margarita y Marisol Melesio, 1986: "Principales grupos étnicos: indígenas y ladinos", en: Miguel Messmacher, Santiago Genovés y Margarita Nolasco (et.al.), Dinámica maya. Los refugiados guatemaltecos, México: FCE.

Olmedo Requena, Luis, 1981: Fe cristiana y violencia revolucionaria, México: CUPSA.

Recinos, Adrián, 1954: Monografía del departamento de Huebuetenango. Guatemala: Ministerio de Educación Pública.

SARG, 1988: Cartas de los refugiados a CNR y CEAR. México: Secretaría de Ayuda a Refugiados Guatemaltecos, No. 18, septiembre.

Siegel, Morris, 1956: Cambio cultural en San Miguel Acatán, Guatemala. Guatemala: Seminario de Integración Social Guatemalteca.

Sobrino, Jon, 1977: "El conocimiento teológico en la teología europea y latinoamericana”, en: Miguel Concha y Jorge Iñiguez, Cristianos por la revolución en América Latina, México: Grijalbo.

Tax, Sol, 1965: Los municipios del altiplano mesooccidental de Guatemala, Seminario de Integración Social Guatemalteca, Ministerio de Educación, Cuadernos No. 9.

Tujab, Gloria, 1987: "Lenguas indígenas que se encuentran en vías de extinción”, en: América Indigena. México: Instituto Interamericano Indigenista, vol. XLVIII, No. 3. 
URNG, 1982: "Proclama unitaria de las organizaciones revolucionarias. Al pueblo de Guatemala”, en: Cuicuilco, año II, número 8, abril de 1982, Revista de la Escuela Nacional de Antropología e Historia, México: ENAH.

Valdés Cifuentes, Héctor, 1985: La iglesia guatemalteca: entre el martirio y la esperanza de un pueblo. Bruselas: Pro Mundi Vita 41.

Valdés Oliva, Arturo, 1965: Lengua indígena de Guatemala. Guatemala: Ministerio de Educación, Cuadernos del Seminario de Integración Social Guatemalteca No. 8.

Vargas, Fernando Jacobo, 1984: Guatemala: sus recursos naturales, el militarismo y el imperialismo. México.

Villa Rojas, Alfonso, 1986: "Configuración cultural de la zona noroeste de Guatemala”, en: Miguel Messmacher, Santiago Genovés y Margarita Nolasco (et.al.), Dinámica maya. Los refugiados guatemaltecos. México: FCE. 